\title{
A compreensão da Física aplicada ao trânsito na perspectiva de egressos do ensino médio, alunos de cursos de primeira habilitação
}

The understanding of traffic applied physics in high school graduates perspective, students of first driver's license courses

\author{
Patrick Alves Vizzotto*, Luiz Fernando Mackedanz \\ Instituto de Matemática, Estatística e Física, Universidade Federal do Rio Grande, Rio Grande, Rio Grande do Sul, \\ Brasil
}

Recebido em 21 de Novembro de 2016. Revisado em 12 de Fevereiro de 2017. Aceito em 12 de Fevereiro de 2017

Este artigo apresenta os resultados de uma pesquisa de mestrado que buscou investigar se egressos do Ensino Médio estabelecem relações entre conteúdos de Física estudados na escola com fenômenos Físicos observados no cotidiano do trânsito, evidenciando se a proposta de ensino orientada pelos documentos oficiais do Ministério da Educação, que sugere um ensino para a vida, está surtindo resultados positivos posteriores a sua formação na escola. Os investigados foram 202 egressos do Ensino Médio, estudantes de autoescolas de Passo Fundo/RS, que responderam a um questionário de múltipla escolha com 10 questões, analisadas com técnicas estatísticas. Como resultado, pode-se constatar que os estudantes não relacionam a Física e o trânsito de forma satisfatória; a qualidade do Ensino Médio e as experiências vivenciadas podem ter sido relevantes para influenciar o bom desempenho de uma parcela menor dos participantes; fatores relacionados com a escola, modelo de ensino, estrutura, assim como professores, relações com os alunos, didática, relações afetivas e metodologia de ensino foram pontos destacados através das análises, sugerindo correlação com a retenção do conhecimento.

Palavras-chave: Ensino de Física, Contextualização, Educação para o Trânsito.

This article presents the results of a master's research that sought to investigate whether graduated in high school establish relationships between the physics contents, studied during the school, with Physical phenomena observed in everyday traffic, showing if the teaching proposal guided by official documents of the Ministério da Educação, that suggest a teaching for life, is having positive results after their training in school. Those submitted were 202 graduated in high school, driving schools students from Passo Fundo/RS, who answered a multiple choice questionnaire with 10 questions, analyzed with statistical techniques. As result, it can be observed that students do not visualize a relationship between physics and traffic; the quality of secondary education and the life experiences could be relevant to influence the good performance of a small portion of the participants; factors related to the school, teaching model, structure; as well as teachers, relationships with students, didacticism, personal relationships and teaching methodology were highlighted points through the analysis, suggesting correlation with knowledge retention.

Keywords: Physics Teaching. Contextualization. Traffic Education.

\section{Introdução}

A vivência de sala de aula permite ao professor de Física perceber que há maior probabilidade do estudante compreender os conceitos físicos na es-

*Endereço de correspondência: patrick.fisica@hotmail.com cola quando são apresentados de forma aplicada ao cotidiano, principalmente se tais contextos estão diretamente ligados à sua realidade.

Considerando o uso cotidiano do automóvel e a quase universalização de acesso à carteira de motorista, os acidentes de trânsito passaram a estar 
presentes no cotidiano de todos, direta ou indiretamente. Nesse contexto, podemos verificar a presença de grande quantidade de conhecimentos físicos intrínsecos, apesar de nem sempre serem percebidos pelos motoristas. Logo, estudar tais conhecimentos está em acordo com o proposto pelos Parâmetros Curriculares Nacionais - PCN [1], ao propor um estudo contextualizado, de maneira a dar significância ao aprendizado do estudante.

Recentemente, a Base Nacional Curricular Comum - BNCC [2] também insiste que "o conhecimento físico, com seus conceitos, leis, grandezas e relações matemáticas, ganha mais significado se utilizado em problemáticas reais,..." (p. 144).

Como ilustração, é possível observar uma comparação entre dados dos últimos 10 anos referentes aos acidentes fatais e número de mortes em estradas estaduais e federais do estado do Rio Grande do Sul [3]. No Gráfico 1, apresentamos a evolução temporal do número de acidentes fatais de trânsito, podendo observar que de 2007 à 2016, a média de acidentes foi de 1716 a cada ano. Já o Gráfico 2 apresenta a evolução temporal do número de mortes fatais, para o mesmo período.

É importante refletir que no período considerado, a população estadual teve um crescimento de $4 \%$, segundo a Fundação de Economia e Estatística Siegfried Emanuel Heuser [4] e o Instituto Brasileiro de Geografia e Estatística [5], aumentando de 10.844.476 para 11.286.500 habitantes. Por outro lado, o número de veículos em circulação no estado aumentou $65 \%$ em relação à 2007 , crescendo de 3.855 .215 para 6.386.619 veículos no ano de 2016, segundo o Detran [6].

Estes índices vem a complementar a análise dos acidentes fatais de trânsito para este período, pois se percebe que há maior frota em circulação nos

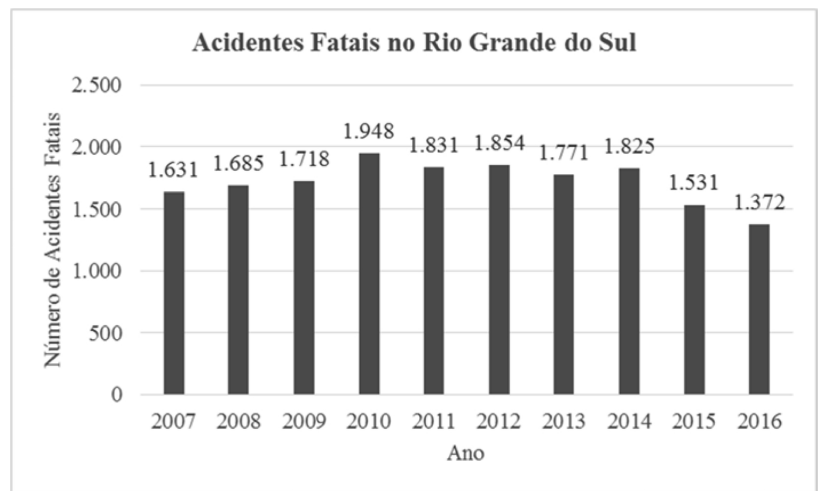

Gráfico 1: Acidentes fatais de trânsito. Fonte: DETRAN/RS (2016a).

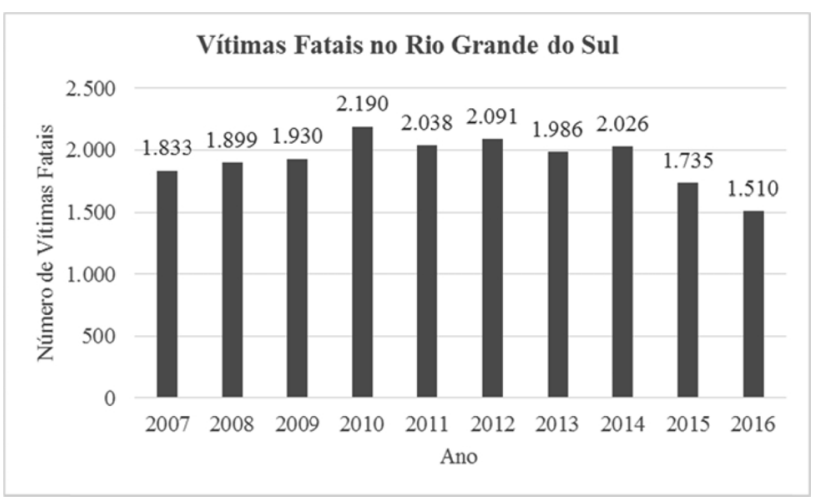

Gráfico 2: Vítimas fatais no trânsito. Fonte: DETRAN/RS (2016a).

últimos anos, o que demonstra ser imprescindível a abordagem de valores presentes na educação para o trânsito em ambientes de aprendizagem, como na escola, por exemplo, pois segundo Negrini Neto [7], um programa de prevenção de acidentes depende sim da educação para o trânsito, mas apresenta também os fatores ligados ao esforço legal e também à engenharia viária e veicular, porém a educação se constitui como um pilar fundamental de sustentação neste tripé (p. 13).

O mesmo autor ainda afirma que a responsabilidade da maioria das mortes no trânsito é devido ao fator causal humano (em torno de 90\%), ou seja, situações em que acidentes poderiam ser evitados se houvesse um maior senso de responsabilidade por parte do condutor frente à perícia que se deve possuir para conduzir um veículo, trazendo além da incalculável perda familiar e social, também um impacto significativo na economia.

Em nível nacional, no ano de 2015 houve um total de 45.501 mortes em acidentes de trânsito [8]. Esse valor poderia ser comparado hipoteticamente a como se houvesse uma queda de avião por dia levando a óbito aproximadamente 116 pessoas em cada queda, trazendo o questionamento sobre o que falta para o ser humano se conscientizar sobre a fragilidade da vida, de modo a não tratar os acidentes de trânsito com naturalidade e sim como um risco que praticamente todos estão vulneráveis atualmente?

Acidentes de trânsito matam de forma esporádica, ao contrário da aviação, onde geralmente um acidente custa dezenas ou centenas de vidas, não sendo nem um, nem outro menos importante, nem deve um ser tratado com maior naturalidade do que o outro, ainda mais que se pode notar também, que 
a faixa etária da maioria dos envolvidos está entre jovens de 18 à 25 anos.

Diante dessas estatísticas, é inevitável não pensar que a educação tenha um papel fundamental na formação e conscientização desses jovens, uma vez que a escola é parte essencial do processo de desenvolvimento do indivíduo na sociedade, e direito de todo cidadão, assegurado pela Constituição Federal.

A partir dessa reflexão, a dúvida que passa a existir é se todo o conhecimento, em especial o científico, ensinado a esse estudante, será lembrado, mesmo que intuitivamente, de modo a possibilitar com que ele o aplique em situações cotidianas, quando efetivamente tornar-se um motorista. Ou, em outras palavras, se houve um aprendizado significativo destes princípios físicos no Ensino Básico.

Um veículo em alta velocidade é um corpo que obedece mais as leis da Física do que aos comandos de um motorista, independentemente de sua habilidade. Portanto, dirigir não consiste somente em aprender algumas técnicas de funcionamento do veículo e assim estar apto a andar pelas ruas. Compreender significativamente fenômenos relacionados com conceitos físicos são fundamentais para a formação de um bom condutor, desenvolvendo habilidades de resolver problemas reais, ao deparar-se com certas situações no futuro, já como efetivo motorista. Portanto, acredita-se que o conhecimento da Física pode auxiliar na compreensão de fenômenos do trânsito, fazendo das aulas da área das Ciências Exatas e da Terra, um lugar privilegiado para estimular tais discussões.

Neste sentido, é importante investigar se indivíduos egressos do Ensino Médio estabelecem relações entre conteúdos de Física estudados durante a escola e fenômenos físicos observados no cotidiano do trânsito. Por esse motivo, o local escolhido para a investigação foi o curso de primeira habilitação de Centros de Formação de Condutores (CFCs), da cidade de Passo Fundo - RS.

Sendo assim, o objetivo do presente artigo é apresentar os resultados quantitativos de uma pesquisa à nível de mestrado que buscou investigar se os estudantes de autoescola estabelecem relações entre conteúdos de Física estudados no Ensino Médio e o cotidiano do trânsito. Essas relações buscam evidenciar se a proposta de ensino orientada pelos documentos oficiais do Ministério da Educação, de ensinar para a vida e formar um cidadão preparado para o cotidiano, está surtindo resultados relevantes posterior à formação do indivíduo na escola.
De forma específica, se buscou verificar os conceitos físicos abordados nos cursos de primeira habilitação dos CFCs; evidenciar as motivações para aprender a dirigir e a vivência do participante com o cotidiano do trânsito; analisar as relações estabelecidas entre conceitos físicos e situações cotidianas; identificar através de entrevista o contexto educacional do ensino de Física de onde vieram os sujeitos. Essas ações buscam traçar um panorama ainda não relatado por pesquisas da área da Física aplicada ao Trânsito: o da assimilação do conhecimento posterior à formação do estudante.

Segundo Urruth [9], de modo geral, existem diversos trabalhos sobre educação para o trânsito no Ensino Fundamental, porém poucos trabalhos são encontrados aplicados no contexto do Ensino Médio, sendo que é nessa faixa etária na qual se encontram a maior parte dos causadores de acidentes.

Desse modo, este fenômeno foi observado através de uma pesquisa Descritiva e Exploratória, onde se parte do pressuposto de que se o indivíduo conhecer os aspectos Físicos do seu mundo, em especial, aplicados ao trânsito, poderá haver maior probabilidade dessa pessoa ser um melhor motorista e pedestre, sendo um indivíduo consciente das relações de causa e efeito de suas ações, podendo assim atuar e influenciar com maior êxito e responsabilidade o mundo no qual se está inserido.

\section{A Física aplicada ao Trânsito}

Considerando que o estudo da Física engloba a interpretação e explicação da natureza, não há como não pensar na grande quantidade de fenômenos aplicados ao trânsito que se pode compreender a partir do conhecimento da Física básica escolar.

Todo professor dispõe intuitivamente de ferramentas das quais se utiliza para desenvolver suas aulas, visando o melhor desempenho de ensino e aprendizagem, constituindo assim seu peculiar método. Sem insinuar qualquer juízo de valor em especifico à qualquer metodologia que os professores venham a adotar atualmente, é necessário considerar que algumas ferramentas são mais efetivas do que outras no despertar de interesse, motivação e consequente aprendizagem dos estudantes.

Outro fato reside na importância de valorizar os saberes que os estudantes trazem para dentro da sala de aula. Esses saberes são desenvolvidos durante suas diversas interações na sociedade e reflexões particulares, constituindo um mundo de certezas 
internas, que se forem errôneas, dificilmente serão desconstruídas contra vontade.

Para Toti e Pierson [10] o cotidiano é percebido como uma possibilidade de se chegar aos conhecimentos prévios dos estudantes, podendo ser dessa maneira, um organizador de referencial comum para se observar os elementos necessários à construção das estruturas de pensamento desejáveis no Ensino de Física. Desse modo, defende-se que essas concepções não devem ser ignoradas pelos docentes, uma vez que influenciam na forma com que novos conhecimentos são interpretados, considerados e por sua vez, legitimados ou não, ou seja, influencia diretamente no processo de aprendizagem do estudante.

Dentro dessa realidade, a contextualização aliada à problematização consiste em uma significativa ferramenta, onde o professor pode utilizá-la como instrumentos facilitadores da construção de significados, conforme salienta Chagas [11]:

A importância do ensino de Física contextualizado ao automóvel não se restringe à compreensão do seu funcionamento, mas também à necessidade de uma maior conscientização por parte dos motoristas, para os perigos que o mau uso desta ferramenta oferece aos seus ocupantes, pois os acidentes de trânsito têm ceifado muitas vidas. (p.25).

Nesse sentido, conceitos de Física e seus fenômenos aplicados à situações observadas no trânsito formam uma listagem extensa de associações, possibilitando essa abordagem em tópicos de praticamente as três séries do Ensino Médio. Essa aliança também proporciona, segundo Brust [12] uma combinação entre a Física e o trânsito, onde se poderá melhorar duas coisas que precisam de atenção no cotidiano: o ensino de Física que será levado para a vida do aluno e a prevenção de acidentes de trânsito.

De acordo com os dados quantitativos sobre acidentes e mortalidades no trânsito, se deve considerar que a violência no trânsito é um assunto que merece atenção da escola, uma vez que esta, busca também a construção de valores e formação da cidadania. Muitos desses acidentes são causados por imprudências e negligências do condutor, que dos muitos motivos que os levam a realizá-las, a falta de informação e conhecimento das causas e efeitos de suas ações pode vir a ser um deles.

Nesse sentido, a Escola e o Ensino de Física ganham notório espaço, possuindo embasamento teórico para atuar na explicação de muitos desses fenômenos percebidos no cotidiano do trânsito, sendo portanto, um contexto de importante relevância a ser abordado nas aulas de Física, além de estarem de acordo com as orientações dos documentos do Ministério da Educação e colaborando para a conscientização, conforme ressalta Joca [13]:

O ensino da Física na Educação para o trânsito no Ensino Médio é mais do que o cumprimento da Lei, de maneira que por meio da Educação será possível reduzir o número de acidentes de trânsito, com consequente diminuição da quantidade de mortos e feridos nas ruas e estradas do país. (p.9).

De modo geral, a conscientização na educação para o trânsito não é um assunto que se constitua no indivíduo em um curto espaço de tempo, ela é sim um processo de construção do ser humano, no qual influencia no seu senso de responsabilidade, respeito pela vida, caráter e zelo pelo bem estar mútuo da sociedade, corroborando para os ideais de liberdade, convívio fraterno e igualdade de direitos de todos os cidadãos, sendo dessa forma, importante buscar desenvolver essa formação desde os primeiros anos do Ensino Fundamental.

\section{Revisão de literatura}

A fim de conhecer a produção nacional sobre a temática "Física aplicada ao trânsito", realizamos uma revisão de literatura. O objetivo de tal revisão foi observar de que forma a temática vem sendo trabalhada no ensino, ou seja, como os professores estão trabalhando a temática em sala de aula e socializando suas experiências em âmbito acadêmico. Para tanto, foram consultados 40 repositórios vinculados ao projeto da IBICT/FINEP, bem como buscas na SciELO (Scientific Electronic Library Online), no Portal de Periódicos da CAPES e em periódicos nacionais Online com Qualis (2016) A e B das áreas de ensino e pesquisa em Educação em Ciências e Ensino de Física. Nos periódicos, foram revisados os últimos 11 anos de publicações (2005 a 2016).

As palavras-chave ou descritores utilizados foram "educação para o trânsito", "Física no trânsito", e "Física aplicada ao trânsito". As sentenças apresentadas foram utilizadas em todas buscas realizadas, onde se obteve um total de 2491 documentos recuperados. Para a seleção dos documentos integrais, foram levados em consideração aspectos como: área do 
conhecimento, objetivos da pesquisa, fundamentação teórica e relação com a presente investigação.

Sendo assim, os 2491 documentos recuperados foram reduzidos para 20 trabalhos, compostos de 8 Dissertações, 8 Artigos em Periódicos e 4 Trabalhos de Conclusão de Curso - TCC.

Os trabalhos convergem para ideias em comum, tais como: a importância de haver um ensino contínuo da educação para o trânsito durante todos os anos da Educação Básica; propostas didáticas utilizando recursos tecnológicos como jogos e simulações; abordagens do tema de forma transversal, interdisciplinar ou multidisciplinar na escola de Ensino Fundamental e médio; análise de propostas de educação para o trânsito a partir de teóricos como Vygotsky, Piaget e Ausubel; importância da contextualização no ensino de Física; influência dos aspectos emocionais na aprendizagem e também discussões sobre os fundamentos dos documentos oficiais para a educação para o trânsito.

As discussões de conceitos físicos aplicados aos automóveis proporcionam a compreensão do funcionamento dos dispositivos que o compõe e dos fenômenos relacionados com a sua utilização. Os trabalhos citados proporcionam extensa abordagem conceitual de tais fenômenos, compondo produtos à disposição dos professores de Ensino Médio para os utilizar. As pesquisas e discussões teóricas sobre a temática, proporcionam embasamentos teóricos e metodológicos para os professores que desejam estabelecer tais relações em sala de aula, compondo subsídios relevantes para o aprofundamento dos professores e posterior aplicação de propostas metodológicas no Ensino Médio.

Ao encontro da presente pesquisa, as contribuições dos trabalhos apresentados proporcionaram conhecer o estado da arte atual da temática à nível nacional, a fim de se utilizar das experiências e produções já realizadas para vislumbrar o avanço da pesquisa dentro da temática.

As produções apresentadas buscam trabalhar aulas de Física ou abordar o tema "trânsito" em diferentes contextos e conceitos. Por exemplo, Gurgel et. al. [14]; Lucena [15]; Viana [16]; Gomes [17] e Kleer [18] buscaram abordar a física a partir da temática das investigações de acidentes de trânsito, contextualizando as aulas de Física, propondo essas discussões como tema transversal na escola, trazendo a realidade da perícia criminal para apresentar o tema aos alunos ou trabalhando com softwares que potencializam cálculos com dados reais de investigações.
Os trabalhos de Abeid [19]; Abeid e Tort [20] [21]; Chagas [11]; Silveira [22]; Di Rocco [23]; Silva [24]; Urruth [9]; Back [25]; Brust [12] e Joca [13], buscam desenvolver o tema a partir dos conceitos, relacionando-os com o trânsito de modo geral, tanto no Ensino Médio como na Graduação, quer em propostas didáticas ou cursos, abordando temas principalmente estudados dentro da Mecânica Clássica.

Pode-se perceber através da pequena quantidade de estudos encontrados, a escassez de pesquisas na área, sendo isso também apontado pela maioria dos pesquisadores analisados na literatura. Outra questão que se pode perceber é a necessidade da educação para o trânsito ser tratada em nível escolar, não somente através de exemplos, mas também por situações problema que possam ser contextualizados, isto é, sejam percebidos pelo motorista em formação como algo já trabalhado em seu tempo escolar.

Assim, se pode considerar a importância da disciplina de Física como formadora de bons cidadãos, motoristas e pedestres, reforçando o caráter social da disciplina.

\section{Metodologia}

Quanto aos objetivos da pesquisa, a presente investigação é de caráter descritivo, com um objeto de estudo baseado em uma amostragem não-probabilística e analisado com base em técnicas da Estatística descritiva e Testes de Hipótese. [26][27][28][29].

A coleta de dados foi realizada através da aplicação de um questionário, inicialmente com dez questões de múltipla escolha, onde cada uma delas consistia de uma situação de Física aplicada ao cotidiano do trânsito, na qual as alternativas seriam os possíveis fenômenos que dariam explicação para tal acontecimento. As questões foram elaboradas pelo pesquisador, tendo como base os elementos físicos apresentados nos capítulos de direção defensiva da apostila do curso de primeira habilitação dos Centros de Formação de Condutores de Passo Fundo/RS [30].

Cada questão criada para o instrumento teve como base o estilo de questões elaboradas para o Exame Nacional do Ensino Médio (ENEM), onde as mesmas apresentam um contexto, onde algum fenômeno físico é apresentado e o conceito que fundamenta o seu funcionamento dentro das alternativas a serem assinaladas, possuindo cada questão um objetivo de avaliar habilidades e competências apresentadas pelos estudantes e orientadas pelos documentos oficiais 


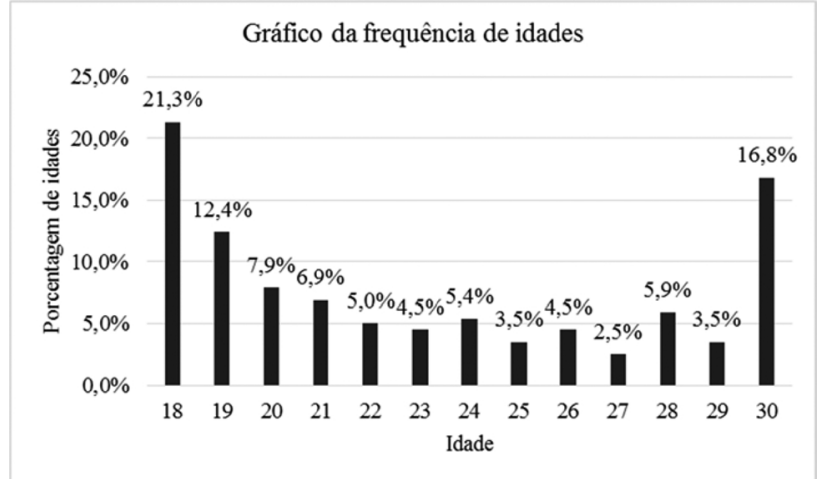

Gráfico 3: Frequência de idade dos participantes. Fonte: autoria própria.

do Ministério da Educação a serem ensinados dentro da área das Ciências da Natureza e suas Tecnologias, em particular.

Antes da aplicação nas autoescolas uma pesquisa piloto foi realizada com um número menor de indivíduos (72) diferentes dos participantes oficiais, porém dentro dos pré-requisitos da pesquisa, que foram Ensino Médio completo e idades entre 18 e 30 anos, a fim de testar a confiabilidade e consistência interna do instrumento criado. O questionário foi validado segundo as exigências da teoria clássica dos testes, obtendo índices como o Alfa de Cronbach de valor 0,74 e sugerindo a exclusão de duas questões (1 e 4) para análise final.

A coleta de dados foi realizada entre os meses de dezembro/2015 e fevereiro/2016 em três Centros de Formação de Condutores da cidade de Passo Fundo/RS. O questionário foi respondido de forma anônima por 202 indivíduos e a participação dos mesmos foi proposta de forma livre e espontânea. As análises estatísticas foram realizadas através do software SPSS ${ }^{\circledR}$ (Statistical Package for the Social Sciences).

\section{Resultados e discussões}

\subsection{Caracterização dos participantes}

A medida da frequência de idades é apresentada no Gráfico 3, onde se pode observar a concentração de estudantes com idades tendendo ao extremo do limite estipulado pela coleta de dados, 43 estudantes com 18 anos e 34 com 30 anos.

Observando as frequências de cada participante também foi possível observar os dados para o ano de conclusão do Ensino Médio, conforme apresentado pelo gráfico 4 .

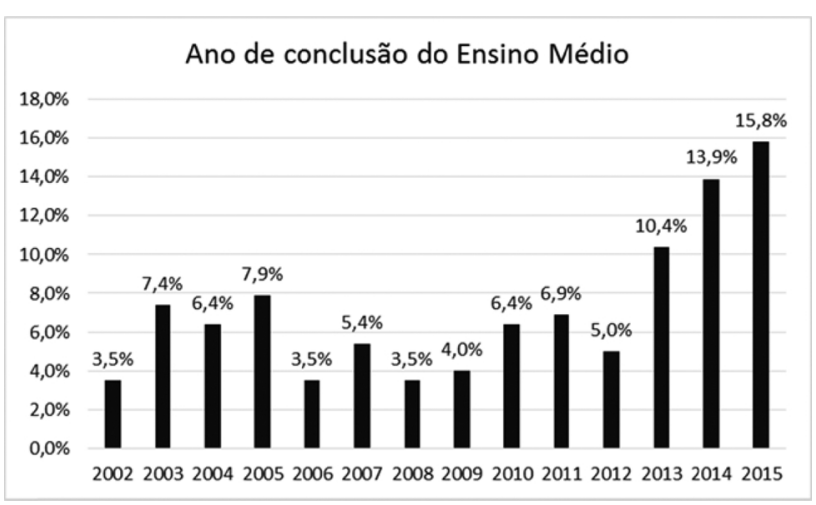

Gráfico 4: Frequência do ano de conclusão do Ensino Médio dos participantes Fonte: autoria própria.

Nota-se que aproximadamente $40 \%$ dos participantes concluíram seus estudos a partir do ano de 2013 e a distribuição dos outros $60 \%$ apresenta-se tendendo à forma homogênea entre os anos de 2002 à 2012, conforme se pode observar no Gráfico 4.

\subsection{Análise das questões}

As questões utilizadas para esta pesquisa encontramse descritas no Apêndice I desta produção, a fim de auxiliar na compreensão dos resultados aqui apresentados. A realização de uma análise particular das questões teve por objetivo explorá-las com maiores detalhes. Primeiramente se analisou as 8 questões validadas e posteriormente as outras 2 que foram excluídas da análise geral de dados.

Os conceitos e fenômenos físicos escolhidos para fazer parte da temática das questões foram:

Questão 1 - Mecânica Clássica - Princípio da Inércia;

Questão 2 - Termologia - Dilatação Térmica;

Questão 3 - Mecânica Clássica - Torque ou Momento de uma Força;

Questão 4 - Mecânica Clássica - Força Centrífuga;

Questão 5 - Aplicado à Mecânica Clássica - Princípio da Conservação de Energia;

Questão 6 - Óptica Geométrica - Reflexão;

Questão 7 - Mecânica Clássica - Atrito - aquaplanagem;

Questão 8 - Mecânica Clássica - Momento linear ou Quantidade de Movimento;

Questão 9 - Mecânica Clássica - Momento linear ou Quantidade de Movimento;

Questão 10 - Óptica Geométrica - Espelhos Planos.

As competências e habilidades propostas pelos documentos oficiais do Ministério da Educação [31] 
também foram citadas, demonstrando que o objetivo de cada questão buscava atender à orientação proposta. As competências e habilidades citadas foram as seguintes:

Competência de área 5 - Entender métodos e procedimentos próprios das ciências naturais e aplicá-los em diferentes contextos.

Competência de área 6 - Apropriar-se de conhecimentos da Física para, em situações problema, interpretar, avaliar ou planejar intervenções científicotecnológicas.

Habilidade 17 - Relacionar informações apresentadas em diferentes formas de linguagem e representação usadas nas ciências Físicas, químicas ou biológicas, como texto discursivo, gráficos, Quadros, relações matemáticas ou linguagem simbólica.

Habilidade 18 - Relacionar propriedades Físicas, químicas ou biológicas de produtos, sistemas ou procedimentos tecnológicos às finalidades a que se destinam.

Habilidade 20 - Caracterizar causas ou efeitos dos movimentos de partículas, substâncias, objetos ou corpos celestes.

Habilidade 21 - Utilizar leis Físicas e (ou) químicas para interpretar processos naturais ou tecnológicos inseridos no contexto da termodinâmica e(ou) do eletromagnetismo.

A Questão 2 embora tenha apresentado mais acertos que erros (66,3\%), a sua segunda alternativa com maior índice de escolha possuía uma divergência teórica que apenas uma leitura atenta e interpretação de textos seriam suficientes para eliminá-la, porém 31 pessoas marcaram essa e outras 37 as outras duas alternativas incorretas, sinalizando a interpretação de textos como um fator indicativo de dificuldade de alguns.

Na Questão 3, se pode observar que os estudantes utilizaram técnicas de eliminação de alternativas, pois essa questão apresentava em duas incorretas assinaladas com menor frequência, conceitos usados exaustivamente pelos professores da $1^{\text {a }}$ Série do Ensino Médio, não correspondendo ao fenômeno abordado na questão, ou seja, se foram marcadas com menor frequência, significa que eles associaram o conceito errado ao estudo desse no Ensino Médio, não correspondendo ele ao fenômeno observado na questão. Logo, isso pode significar que as técnicas comumente utilizadas para otimização de tempo e eliminação de alternativas incorretas em vestibulares e provas em geral, continuaram sendo utilizadas como método lógico de análise de questão.
A Questão 5 que discutia o Princípio de Conservação de Energia apresentou um índice de acertos menor que o de erros. Como a questão versava sobre acidentes de trânsito, as alternativas mais assinaladas envolviam palavras como "colisões" e "força", de modo que se pode imaginar que aos que não sabiam o conceito correto da questão, buscaram através da escolha aleatória (chute) a alternativa com base nas palavras contidas na sua descrição.

Na Questão 6, 74,8\% dos participantes responderam corretamente essa questão, demonstrando uma diferenciação satisfatória da maioria, para os conceitos de Reflexão, Refração, Dispersão e Polarização.

Embora mais da metade dos participantes tenham acertado a questão 7 , que versava sobre o fenômeno da aquaplanagem, a segunda alternativa mais assinalada continha a palavra "velocidade", sendo escolhida por 37 estudantes, o que pode significar uma relação intuitiva entre a alta velocidade e a ocorrência do fenômeno.

A Questão 8 possuiu uma distribuição mais homogênea entre as alternativas assinaladas, apenas $31,7 \%$ dos estudantes acertaram a explicação que fundamenta o uso e importância do airbag. A relação significativa entre o fenômeno e o conceito não é evidenciada nessa questão, levando em consideração os índices apresentados.

Da mesma forma, a Questão 9 demonstra que os entrevistados relacionaram intuitivamente o conceito de potência do veículo com a sua velocidade permitida, para justificar a diferença de velocidade de veículos com diferentes massas nas rodovias. As relações intuitivas realizadas nos questionários demonstraram que o intuitivo geralmente não é realizado com base nos conceitos corretos, porém são utilizadas relações cotidianas juntamente com raciocínios indutivos para se chegar à uma possível explicação.

A Questão 10 por sua vez, apresentou uma situação comumente observada, porém pouco compreendida, a das letras invertidas nos veículos de emergência. Se analisarmos os índices de acertos e erros no questionário ( $48 \%$ de acertos), se poderá notar que menos da metade dos estudantes acertaram essa questão que apresentava conceitos da Óptica Geométrica, porém a presença desse fenômeno no cotidiano, seja pessoalmente ou na mídia, poderia ter sido relacionado significativamente em suas aulas de Física com maior ênfase.

A Questão 1, eliminada junto com a questão 4 da análise geral devido às orientações do processo 
de validação do instrumento, abordou a Primeira Lei de Newton, assunto mais lembrado pelos estudantes. As três Leis são um dos primeiros assuntos estudados geralmente na $1{ }^{a}$ Série do Ensino Médio, porém embora os estudantes tenham maior lembrança do nome dos conceitos, os fenômenos à eles atribuídos são confundidos, conforme se pode observar nos índices de acertos e erros apresentado para essa questão.

E por fim na Questão 4, também obteve mais erros do que acertos, e o conceito de força centrífuga não foi bem compreendido pelos estudantes, onde atribuíram com $31,7 \%$ à letra $\mathrm{A}$, que descrevia o acontecimento dos carros invadirem a pista contrária à força Peso.

De modo geral, se percebeu um público-alvo heterogêneo, vindos de diferentes realidades e por consequência, diferentes desempenhos. Suas formações demonstram o quanto a educação e as experiências vividas por cada um pode influenciar na constituição do cidadão que egressa da Educação Básica.

Observando os variados desempenhos das diferentes categorias onde eles foram classificados, se pode efetivamente constatar o que já é consenso entre professores e pesquisadores: o estudante que é estimulado, que possui oportunidades de vivenciar um aprendizado em um ambiente rico de discussões, observando aplicações com o mundo no qual está inserido e assim, se motiva e aproveita essas oportunidades, terá maiores condições de aprender com maior qualidade.

\subsection{Análise dos Índices de acertos, dificuldade e facilidade das questões}

Como se pode observar no Gráfico 5 , com base no índice de acertos, as questões 5,8 e 9 podem ser consideradas as de maior dificuldade do questionário.

O índice de facilidade e dificuldade das questões pode ser observado pela porcentagem de acertos e erros de cada item. A observação dos itens para considerá-los como fáceis, médios ou difíceis consiste em calcular a porcentagem de acertos. As questões que obtiverem $80 \%$ ou mais de acertos são consideradas como fáceis, na mesma lógica as questões que obtiverem $20 \%$ ou menos de acertos, são consideradas difíceis e as que estiverem dentro da faixa de 21 à $79 \%$ são consideradas questões médias [32]. O Quadro 1 demonstra as informações necessárias para concluir o índice.

Conforme observado, é possível notar que todas as questões estão dentro da faixa aceitável para

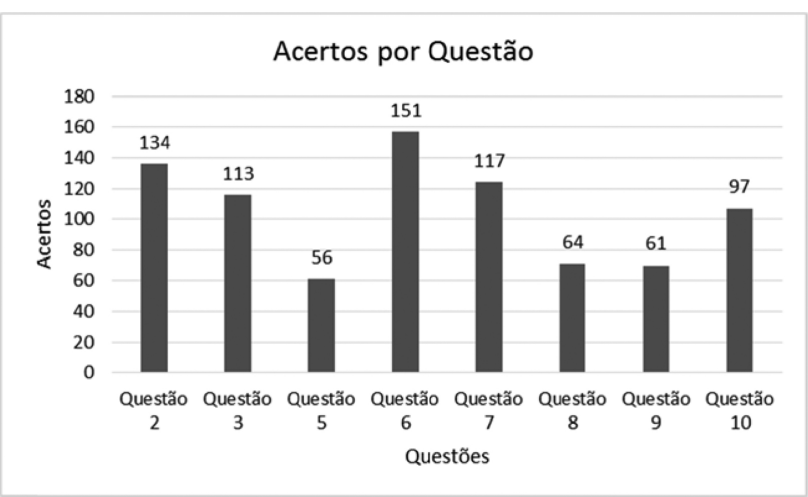

Gráfico 5: Índice de acertos por questão Fonte: autoria própria.

considerar um item como válido dentro dos limites, não compondo um instrumento com questões muito fáceis nem muito difíceis (entre 20 à $80 \%$ de acertos).

\subsection{Estatística Descritiva sobre o questionário aplicado: Medidas de Tendência Central e Dispersão geral dos dados}

As medidas de tendência central consideradas para esta análise foram a média, moda e mediana. Dessa forma, a saída desses cálculos pelo SPSS forneceu o Quadro 2 que apresenta as referidas medidas e as frequências gerais de acertos por pessoa, análise que também oferece uma visão detalhada de quantos indivíduos obtiveram o valor máximo do escore total sinalizado.

De modo geral, os 202 participantes da pesquisa apresentaram resultados abaixo dos $50 \%$ de acertos, sendo que os que acertaram mais questões, acertaram 7 itens apenas, o que leva a constatar que o máximo desempenho obtido no questionário foi de $87,5 \%$.

Como nem sempre as medidas de tendência central podem ser consideradas fidedignas para apontar

Quadro 1: Relação de itens, porcentagens de acertos e índice de facilidade. Fonte: autoria própria.

\begin{tabular}{llll}
\hline Questão & Acerto & \multicolumn{2}{l}{ Porcentagem de acertos } \\
\hline 2 & 13 & 66 & média \\
3 & 11 & 56 & média \\
5 & 56 & 28 & média \\
6 & 15 & 75 & média \\
7 & 11 & 58 & média \\
8 & 64 & 32 & média \\
9 & 61 & 31 & média \\
10 & 10 & 53 & média \\
\hline
\end{tabular}


Quadro 2: Medidas de tendência central, dispersão e frequência geral de acertos por pessoa. Fonte: autoria própria.

\begin{tabular}{|c|c|c|}
\hline \multicolumn{3}{|c|}{ acertos_por_pessoa } \\
\hline $\mathrm{N}$ & Valid & 202 \\
\hline & Missing & 0 \\
\hline Mean & & 3,92 \\
\hline Median & & 4,00 \\
\hline Mode & & $2^{\mathrm{a}}$ \\
\hline Std. Deviation & & 1,726 \\
\hline Minimum & & 0 \\
\hline Maximum & & 7 \\
\hline
\end{tabular}

\begin{tabular}{ccccc}
\multicolumn{5}{c}{ acertos_por_pessoa } \\
\hline Valid & 0 & Frequency & Percent & Cumulative Percent \\
& 1 & 4 & 2,0 & 2,0 \\
& 8 & 41 & 20,3 & 5,9 \\
& 3 & 29 & 14,4 & 26,2 \\
4 & 39 & 19,3 & 40,6 \\
5 & 41 & 20,3 & 59,9 \\
6 & 26 & 12,9 & 80,2 \\
& 7 & 14 & 6,9 & 93,1 \\
& Total & 202 & 100,0 & \\
\hline
\end{tabular}

a. Multiple modes exist. The smallest value

is shown

para conclusões, as medidas de dispersão auxiliam a observar o comportamento dos dados. Sendo assim, além dos valores mínimo e máximo apontados pelo Quadro 2, o desvio padrão de valor 1,726 auxiliará a traçar inferências para responder a pergunta problematizada pela presente pesquisa.

A análise da frequência geral de acertos corrobora os valores apontados pelas medidas de tendência central e mostra que 4 estudantes não acertaram nenhuma questão, seguidos de 78 estudantes que não obtiveram um escore mínimo apontado pela mediana (4 acertos). O Quadro 2 também possibilita observar que 14 estudantes tiveram o desempenho máximo dentro dos limites da amostra (7 acertos) e que nenhum dos participantes acertou as 8 questões consideradas.

\subsection{Testes de hipótese}

Para fazer inferências sobre as influências das características da população sobre seu desempenho foi realizado uma série de testes de hipóteses onde uma hipótese dita "nula" poderia ser aceita ou rejeitada conforme os índices apontassem os fatores como influenciadores ou não na distribuição das médias de acertos do grupo estudado. Um teste de hipótese necessita obedecer alguns pré-requisitos específicos para se adequar à metodologia proposta pela literatura. Dentre eles, estão a necessidade de pertencer ou não à uma distribuição normal e possuir as variâncias consideradas como homogêneas.

Os testes de hipóteses tiveram como objetivo verificar se o cruzamento entre condições apresentadas pelos entrevistados apresentariam elementos que au- xiliassem na discussão de quais fatores influenciaram o desempenho desses estudantes na pesquisa.

Cinco testes não-paramétricos foram realizados, pelo fato de que a não distribuição normal dos escores do índice de acertos não possibilitou com que um teste paramétrico (como o Teste $t$ para amostras independentes) fosse realizado. Dessa forma, se optou pelo teste que compara a diferença de médias para dados não-paramétricos, o Teste U de MannWhitney. Esse teste cria um ranking de todos os casos e depois compara estes rankings entre cada um dos grupos.

Realizado no SPSS, o Output do Teste U de MannWhitney fornece o rank médio e a soma dos rankings de cada grupo para que possam ser comparadas e desse modo, verificar se há ou não uma diferença considerada significativa entre os grupos, considerando que quanto maior a diferença, maior a probabilidade de que os dois grupos sejam diferentes em suas características de desempenho.

Dos cinco testes realizados (1- teste para verificar se havia diferença na distribuição de acertos entre gêneros diferentes; 2- teste entre estudantes formados em escola pública e privada; 3 - teste entre estudantes com experiência em dirigir e os sem experiência com veículos; 4- teste entre estudantes de níveis escolares diferentes; e 5- teste de hipótese para faixas etárias diferentes), apenas dois (testes 2 e 3) apresentaram resultados no qual indicaram a rejeição da hipótese nula, ou seja, houve diferença significativa na média de acertos entre estudantes egressos de escolas públicas e particulares, assim como também houve diferença nos escores daqueles que já haviam dirigido antes de fazer a carteira 
de habilitação, quando comparados aos que nunca haviam dirigido.

Com base no observado por esses resultados, se verifica que eles corroboram para a concepção de que é a formação básica e sua qualidade, assim como as experiências de cada indivíduo que podem colaborar para que eles consigam observar o mundo, em especial o mundo da Física e do trânsito juntos, como seres atuantes daquela realidade.

O fator "escola" (diferença entre pública e privada), auxilia a explicar a diferença de desempenho entre os estudantes, assim como os estudantes que já haviam dirigido antes do curso no CFC, eles também podem ter adquirido capacidades intuitivas de compreender os fenômenos físicos através de suas vivências, dando-lhes maior capacidade de aliar teoria na prática.

Interpretar e assumir uma posição de protagonista é uma tarefa que exige uma formação que leve o estudante ao raciocínio crítico e ao estabelecimento de conexões entre teorias e práticas presentes em seus cotidianos de forma efetiva. Da mesma forma com que demonstra a importância de não negar os conhecimentos que o estudantes trazem para a sala de aula, uma vez que todos já ingressam na escola com conhecimentos prévios que podem auxiliar em suas compreensões de mundo, aliando ao que será estudado no decorrer da Educação Básica.

\section{Conclusões}

O objetivo deste artigo foi apresentar os resultados quantitativos de uma pesquisa à nível de mestrado que buscou investigar se os estudantes de autoescola estabelecem relações entre conteúdos de Física estudados no Ensino Médio e o cotidiano do trânsito, a fim de notar se a proposta de ensino orientada pelos documentos oficiais do Ministério da Educação, de ensinar para a vida e formar um cidadão preparado para compreender de forma significativa o cotidiano, está surtindo resultados relevantes posterior à formação do indivíduo na escola.

Com base nos resultados da pesquisa, na vivência observada no processo de coleta de dados e contato com o público-alvo, se mostrou que responder essa questão foi uma tarefa desafiadora, considerando os diversos fatores que influenciam e justificam alguns acertos e erros dos entrevistados, tendo em vista que nem sempre esses fatores são de responsabilidade dos estudantes, sendo atribuídos também ao sistema escolar e à metodologias do professor.
Dessa forma, seria injusto responder a problemática da pesquisa de forma dicotômica, com um "sim" ou um "não", pois há muito o que se considerar para encontrar indicativos de relação, sendo que não é objetivo do Ensino Médio, a simples memorização de conceitos, e sim, suscitar uma autonomia representada pela compreensão, assimilação e aplicação dos assuntos estudados em situações gerais do cotidiano e não somente à um exemplo em específico dado pelo professor.

A problemática da pesquisa visou investigar se egressos do Ensino Médio relacionavam a Física da escola com o cotidiano do trânsito, de modo que as respostas advindas desta pesquisa de forma alguma encerram as inquietações da temática, uma vez que aspectos peculiares referentes à estrutura da escola, à prática pedagógica do professor e até mesmo a relação entre aluno e a disciplina, apontam para questionamentos que podem nortear a continuidade e aprofundamento da investigação, de modo a se buscar formas de potencializar as correlações entre Física e cotidiano.

Quantitativamente, as medidas de tendência central obtiveram os seguintes valores para o escore de acertos: Média: 3,92; Moda: 4, e para a Mediana, houveram dois valores, sendo que o menor apresentado pela saída do SPSS foi: 2; Desvio Padrão: 1,7; Valor mínimo: 0 e Valor máximo: 7.

Esses valores por si só, demonstram que a concentração de acertos aponta para um desempenho médio individual de quase $50 \%$, considerando somente as 8 questões, ou seja, por mais que um desempenho de $50 \%$ signifique metade, a princípio não pode ser considerado como satisfatório, uma vez que os participantes já haviam concluído seus estudos escolares e estavam em um processo de formação complementar em um CFC, ou seja, já haviam estudado a Física básica que poderia fornecer subsídios para compreenderem tais conceitos e fenômenos abordados no questionário.

Esta pesquisa pode concluir que as condições que podem ter influenciado no desempenho individual dos participantes perpassam a formação básica e sua qualidade, assim como as experiências de cada indivíduo, que podem colaborar para que eles consigam observar o mundo, em especial o mundo da Física e do trânsito juntos, podendo atuar dentro dessa realidade específica de forma responsável e crítica, compreendendo as relações de causa e efeitos de suas ações, que por consequência, pode vir 
a formar um cidadão, pedestre e motorista mais consciente.

Conclui-se também, através dos Testes de hipótese, que o fator "escola" auxiliou a explicar a diferença de desempenho entre os estudantes, uma vez que alunos que estudaram em escolas particulares obtiveram desempenhos significativamente melhores que os participantes que concluíram seus estudos em escolas públicas, assim como os estudantes que já haviam dirigido antes de ingressar em uma autoescola, pois tais vivências podem ter proporcionado capacidades intuitivas para compreender os fenômenos físicos abordados em situações aplicadas, podendo ter auxiliado na articulação entre teoria e prática.

Tais resultados convergem para o que os autores da área, como Urruth [9]; Back [25]; e Brust [12] também apontam em relação à importância de haver um ensino contínuo da educação para o trânsito durante todos os anos da Educação Básica, abordando tal temática de forma transversal, interdisciplinar, ou ainda, de forma disciplinar, reforçando a oportunidade da Física articular tais conhecimentos em situações aplicadas, salientando assim, o papel da contextualização no ensino de Física, conforme defendem os autores Abeid e Tort [20]; Chagas [11]; e Silveira [22].

Sabe-se que um indivíduo aprende por meio de vivências particulares e por meio da escola. É inegável o quanto o conhecimento escolar, em especial o da Física pode proporcionar maiores condições de compreensão do mundo, principalmente os fenômenos relacionados ao trânsito, corroborando para o que os documentos da educação denominam como "ensinar para a vida", se utilizando das mais variadas estratégias, entre elas as interdisciplinares ou contextualizadas para atingir tal êxito.

Muitas estratégias de ensino consideradas "inovadoras", baseadas em conhecimentos da psicologia cognitiva, ou que buscam envolver o estudante ativamente na sala de aula são realizadas, testadas e apresentadas no mundo acadêmico do Ensino de Física, porém a aprendizagem não acontece somente na escola, assim como não se dá do dia para a noite e sim, exige certo intervalo de tempo para que a retenção possa acontecer e posteriormente ser observada de forma direta ou indireta, reforçando o viés da investigação relatada na dissertação, socializada neste artigo.

Com esta pesquisa, se pode observar que os efeitos posteriores à formação do estudante na escola sugerem que a aprendizagem não possibilitou, para este grupo em particular, significativas articulações entre a Física e o cotidiano do trânsito, do ponto de vista da retenção conceitual, de modo que os objetivos de um ensino para a vida e formação crítica do indivíduo para compreender o seu cotidiano, não foram alcançados de forma satisfatória.

\section{Apêndice I - Questionário de pesquisa}

- Idade

- Sexo:

- Ano de conclusão do ensino médio:

- Concluiu em: ( ) Escola Particular; ( ) Escola Pública.

- Nível educacional atual: ( ) Ensino Médio; ( ) Graduação; ( ) Pós-Graduação.

- Já dirigiu veículos antes da autoescola? ( ) Sim ( ) Não

\section{Relacionar a situação cotidiana do trânsito com a opção correspondente à explicação física para a ocorrência de tal fenômeno:}

1. Um motorista sem cinto de segurança, trafegando com velocidade de $90 \mathrm{~km} / \mathrm{h}$ observa, a poucos metros de distância, um policial com um radar eletrônico. No mesmo momento ele pressiona o freio e percebe seu corpo sendo projetado para frente, fazendo-o quase encostar o abdome no volante. Qual alternativa demonstra como a Física explica essa projeção do homem para frente?

a( ) Esse fenômeno é conhecido como $1^{\circ}$ Lei de Newton ou Princípio da Inércia, onde todo objeto permanece em estado de repouso ou de movimento em linha reta com velocidade constante, a menos que uma força resultante seja exercida sobre o mesmo.

b( ) Esse fenômeno é conhecido como $3^{\circ}$ Lei de Newton ou Princípio da Ação e Reação, onde sempre que um objeto exercer uma força sobre um segundo objeto, este exercerá uma força de mesmo módulo e orientação contrária sobre o primeiro.

c( ) Esse fenômeno é conhecido como $2^{\circ}$ lei de Newton ou Princípio Fundamental da Dinâmica, onde a aceleração produzida por uma força resultante exercida sobre um objeto é diretamente proporcional à força resultante, possui a mesma orientação desta e é inversamente proporcional à massa do objeto.

d( ) Esse fenômeno demonstra o Princípio da Conservação do Momentum, onde na ausência de uma força externa resultante, o momentum antes de um evento que envolva apenas forças externas é igual ao momentum após o evento.

2. Paga-se mais pela gasolina em um dia quente ou em um dia frio? Um carro é abastecido com o 
mesmo volume de combustível em dois dias diferentes. No primeiro dia a temperatura é de $10^{\circ} \mathrm{C}$ e a quantidade colocada é suficiente para viajar por $200 \mathrm{~km}$. No segundo dia o mesmo volume de combustivel é abastecido, porém a temperatura é de $28^{\circ} \mathrm{C}$, sendo que essa quantidade foi suficiente para rodar somente $170 \mathrm{~km}$. Qual alternativa demonstra como a Física pode justificar a diferença de quilometragem rodada nas duas situações diferentes?

a( ) A diferença de quilometragem é explicada através do Princípio de Bernoulli, onde um fluido que se move uniformemente sem atrito ou perda de energia, a pressão diminui quando a velocidade do fluido aumenta.

b( ) O Princípio de Pascal demonstra que a variação de pressão produzida em uma região qualquer de um fluido em repouso, confinado a um recipiente, é transmitida integralmente através do fluido, justificando a diminuição da quilometragem.

c( ) O aumento da temperatura em qualquer substância faz com que as moléculas se agitem com maior velocidade, ocasionando geralmente uma dilatação no volume. Para uma mesma massa, temperaturas diferentes podem indicar que elas ocupem volumes diferentes.

d( ) O produto da pressão pelo volume é constante para uma dada massa de gás confinado, sem importar as variações individuais da pressão e do volume, desde que a temperatura se mantenha constante, justificando a diminuição da quilometragem.

3. Uma pessoa começa a tentar girar os parafusos de um pneu furado, ela sente certa dificuldade em realizar uma força suficiente que os façam entrar em rotação, sendo que sua chave de roda tem um comprimento de $25 \mathrm{~cm}$. Ela percebe que adicionar uma barra de ferro de $75 \mathrm{~cm}$ à sua ferramenta, permite um esforço menor, conseguindo assim, retirar os parafusos do pneu. Qual alternativa demonstra o conceito Físico que explica como foi possível girar os parafusos depois que o tamanho da chave de roda foi aumentada?

a( ) A velocidade escalar é a velocidade angular multiplicada pelo raio da trajetória. A velocidade angular existe em movimentos circulares e é a derivação da posição angular em função do tempo.

b( ) O torque é a grandeza física que inclui o módulo, a direção e o sentido da força aplicada e também a distância do ponto de aplicação até o eixo. O torque, ou a tendência de girar é grandeza que governa o movimento de rotação de um corpo extenso e o seu módulo aumenta quando a força se distancia do eixo.

c( ) A aceleração centrípeta, também chamada de aceleração normal ou radial, é a aceleração originada pela variação da direção do vetor velocidade de um móvel, característico de movimentos curvilíneos ou circulares. Ela é perpendicular à velocidade e aponta para o centro da curvatura da trajetória. d( ) Impulso é a grandeza física que mede a variação da quantidade de movimento de um objeto. É causado pela ação de uma força atuando durante um intervalo de tempo. Uma pequena força aplicada durante muito tempo pode provocar a mesma variação de quantidade de movimento que uma força grande aplicada durante pouco tempo.

4. Ao se aproximar de uma curva a velocidade deve ser reduzida. Se o motorista negligencia esse procedimento e a efetua com uma velocidade acima do recomendado, pode-se observar que o veículo sofre certa resistência a efetuar a curva dentro do seu lado da faixa, tendendo a invadir a pista contrária (curva para a direita) ou a ir para o acostamento da sua pista (curva para a esquerda). Qual alternativa demonstra qual fenômeno Físico se pode observar nessas situações?

a( ) Ele acontece devido a Força Peso, que é a força que um objeto exerce sobre uma superfície de apoio, que frequentemente, mas nem sempre, se deve à força da gravidade.

b( ) Isso se deve ao Torque, que é a grandeza que governa o movimento de rotação de um corpo extenso do mesmo modo que a força é a grandeza que governa o movimento de translação. O torque, ou a tendência de girar aumenta quando a força se distancia do eixo.

c( ) Acontece devido a Força Normal, que é uma força de reação que a superfície faz em um corpo que esteja em contato com esta, essa força é normal à superfície (perpendicular).

d( ) Isso se deve à Força Centrífuga, que atua do centro para fora da curva. A força centrífuga só tem validade em um referencial ligado ao objeto que gira, por isso ela é chamada também de força inercial centrífuga, percebida apenas por observadores em referenciais não-inerciais de movimento de rotação em relação a um referencial inercial.

5. Percebe-se que veículos com ano de fabricação mais antigo possuem maior resistência quando os observamos em uma colisão, por exemplo. Observase também que os carros fabricados atualmente são mais suscetíveis a amassar do que se comparados com os veículos antigos. Isso pode parecer negativo em um primeiro momento, mas a Física pode explicar porque isso é importante para reduzir aos passageiros as consequências de uma colisão. Qual alternativa explica o que fundamenta esse raciocínio?

a( ) Princípio da Conservação da Energia Mecânica. A energia não pode jamais ser criada ou destruída; ela pode ser transformada de uma forma em outra, mas a quantidade total de energia se mantém constante.

b( ) Nas Colisões inelásticas os corpos envolvidos ficam deformados e/ou produzem calor durante a mesma e possivelmente acabam unindo-se. 
c( ) Princípio da conservação do Momentum, onde ele é conservado em todas as colisões, sejam elas elásticas ou inelásticas, desde que forças externas não interfiram no movimento dos corpos em questão.

d( ) Impulso que é a grandeza física que mede a variação da quantidade de movimento de um objeto. É causado pela ação de uma força atuando durante um intervalo de tempo.

6. A filha de José tem 7 anos e está em uma fase em que questiona todas as coisas que a deixa curiosa. Andando de carro por uma rodovia a noite com seu pai, ela percebe que conforme o veículo se movimenta a sinalização da estrada se ilumina, fazendo-a questionar seu pai sobre o porquê disso acontecer, perguntando: "Como as luzes da estrada sabem quando os carros vão passar para acenderem automaticamente?" Qual alternativa você acha que contém a resposta que José deve dar a sua filha para responder corretamente a esse questionamento?

a( ) O material da sinalização possui a propriedade de refratar a luz dos faróis.

b( ) O material da sinalização possui a propriedade de dispersar a luz dos faróis.

c( ) O material da sinalização possui a propriedade de refletir a luz dos faróis.

d( ) O material da sinalização possui a propriedade de polarizar a luz dos faróis.

7. Um homem dirige sob forte chuva e com velocidade acima do recomendável para o trecho. Ao passar por uma área da estrada totalmente coberta por água, ele sente que perdeu o controle de seu carro por alguns instantes, como se ele tivesse deslizado em cima da pista molhada. Esse fenômeno é conhecido como aquaplanagem: a perda de contato do veículo com o solo pela existência de uma camada de água debaixo do pneu. Qual alternativa demonstra como a Física explica o porquê do seu carro ter deslizado sobre a água?

a( ) Ele acontece devido a velocidade terminal, que é a velocidade atingida quando cessa a aceleração de um objeto, quando a resistência do ar equilibra seu peso.

b( ) Quando isso acontece a superfície fica lisa, fazendo com que o coeficiente de atrito seja praticamente zero. A palavra atrito refere-se à resistência que os corpos opõem quando se movem uns sobre os outros e é causado pelas irregularidades entre as superfícies em contato.

c( ) Ele acontece devido a Força Peso, que é a força que um objeto exerce sobre uma superfície de apoio, que frequentemente, mas nem sempre, se deve à força da gravidade.

d( ) Ele acontece devido à $3^{\circ}$ Lei de Newton ou Princípio da Ação e Reação, onde sempre que um objeto exercer uma força sobre um segundo objeto, este exercerá uma força de mesmo módulo e orientação contrária sobre o primeiro.
8. Não há dúvidas da importância do cinto de segurança para amenizar as consequências de um acidente. Mesmo assim há outros dispositivos de segurança que auxiliam a evitar danos aos passageiros como o Airbag por exemplo, que tem por função amortecer o impacto do corpo do passageiro com o painel e para-brisa do veículo. Qual alternativa explica fisicamente porque, na falha do cinto de segurança, esse dispositivo em especial é importante?

a( ) O Airbag atua reduzindo a Potência mecânica da pessoa até zero. Essa redução é praticamente instantânea quando um passageiro colide diretamente contra o painel ou o para-brisa do veículo.

b( ) O Airbag atua reduzindo a aceleração centrípeta, também chamada de aceleração normal ou radial, é a aceleração originada pela variação da direção do vetor velocidade de um móvel, característico de movimentos curvilíneos ou circulares. Ela é perpendicular à velocidade e aponta para o centro da curvatura da trajetória.

c( ) O Airbag atua reduzindo o Impulso, que é a grandeza física que mede a variação da quantidade de movimento de um objeto. É causado pela ação de uma força atuando durante um intervalo de tempo.

$\mathrm{d}($ ) O Airbag atua prolongando o intervalo de tempo durante o qual a Quantidade de Movimento da pessoa é reduzido a zero. Essa redução é praticamente instantânea quando um passageiro colide diretamente contra o painel ou o para-brisa do veículo. Um intervalo de tempo maior reduz a força e diminui a desaceleração produzida.

9. Normalmente pode-se observar na sinalização das rodovias que para um mesmo trecho, carros de passeio, ônibus e caminhões, possuem limites de velocidade diferentes, como por exemplo $110 \mathrm{~km} / \mathrm{h}$ para carros de passeio, $90 \mathrm{~km} / \mathrm{h}$ para ônibus e 80 $\mathrm{km} / \mathrm{h}$ para caminhões. Isso acontece porque parar um carro é mais fácil do que parar um caminhão ou um ônibus, ambos estando com a mesma velocidade. Qual alternativa demonstra como a Física explica porque essa diferença de velocidade é plausível, uma vez que as condições da estrada são as mesmas para as diferentes categorias de veículos?

a( ) A diferença é devida ao conceito de Momentum Linear ou Quantidade de Movimento de um corpo. A quantidade de movimento de um carro a $110 \mathrm{~km} / \mathrm{h}$ é menor que a de um caminhão a $80 \mathrm{~km} / \mathrm{h}$.

b( ) A diferença é devida ao conceito de Potência de um corpo. A Potência de um carro a $110 \mathrm{~km} / \mathrm{h}$ é menor que a de um caminhão a $80 \mathrm{~km} / \mathrm{h}$.

c( ) A diferença é devida ao conceito de Atrito de um corpo. O atrito de um carro é maior do que o de um caminhão.

d( ) A diferença é devida ao conceito de Rendimento Mecânico de um corpo. O Rendimento Mecânico de um 
carro a $110 \mathrm{~km} / \mathrm{h}$ é menor que a de um caminhão a 80 $\mathrm{km} / \mathrm{h}$.

10. No trânsito, uma situação normalmente vivenciada é quando veículos oficiais como os da polícia, bombeiros ou uma ambulância acionam suas sirenes para passar pelo trânsito de modo a atenderem suas demandas. Pode-se observar que esses veículos possuem as inscrições invertidas lateralmente em sua parte da frente, isso se deve ao fato de que quem está dirigindo um veículo na frente de uma viatura e olha pelo espelho retrovisor, poderá ler corretamente qual viatura é aquela, facilitando assim, a identificação do veículo oficial para o deixar passar. Qual fenômeno Físico acontece no espelho para que a imagem de um corpo seja vista de forma invertida?

a( ) Observa-se a imagem invertida devido a Refração. A luz, proveniente do meio 1, atravessa a superfície de separação entre os dois meios e passa a se propagar no meio 2, sendo a luz, em geral, desviada, assumindo uma direção bem diferente da direção de propagação no meio 1 .

b( ) Acontece devido ao fenômeno da Dispersão da luz, que acontece quando uma luz policromática, ao se refratar, decompõe-se nas cores componentes. Esse fenômeno se deve ao fato de que o índice de refração de qualquer meio material depende da cor da luz incidente.

c( ) O espelho retrovisor é um exemplo de um Espelho Plano. Os raios que partem de um objeto, diante de um espelho plano, refletem-se no espelho e atingem nossos olhos. Assim, recebemos raios luminosos que descreveram uma trajetória angular e temos a impressão de que são provenientes de um objeto atrás do espelho, em linha reta, isto é, mentalmente prolongamos os raios refletidos, em sentido oposto, para trás do espelho.

$\mathrm{d}$ ( ) Acontece devido à sombra e a penumbra. Quando um corpo opaco é colocado entre uma fonte de luz e um anteparo é possível delimitar tais regiões. A sombra é a região do espaço que não recebe luz direta da fonte. Penumbra é a região do espaço que recebe apenas parte da luz direta da fonte, sendo encontrada apenas quando o corpo opaco é posto sob influência de uma fonte extensa.

\section{Referências}

[1] BRASIL, PCN do Ensino Médio: Parâmetros Curriculares Nacionais. Ciências da Natureza. Matemática e suas Tecnologias (Mec/Semtec, Brasília, 2000).

[2] BRASIL, Base Nacional Comum Curricular. 2a ed. revista. Disponível em http: //basenacionalcomum.mec.gov.br/documentos/ bncc-2versao.revista.pdf, acesso em 05 Out. 2016.

[3] DETRAN/RS Departamento Estadual de Trânsito, Diagnóstico da acidentalidade fatal no trânsito:
2016. Assessoria Técnica, de Gestão e Planejamento. Sistema de Consultas Integradas - SJS/RS. Disponível em http://www.detran.rs.gov.br/ conteudo/33739/diagnostico-de-2015, acesso em Jan. 2017.

[4] FEE Fundação de Economia e Estatística Siegfried Emanuel Heuser, Estimativas Populacionais - Revisão 2015. 2015. Disponível em http://www.fee.rs.gov.br/indicadores/ populacao/estimativas-populacionais/ acesso em Jan. 2017.

[5] IBGE Instituto Brasileiro de Geografia e Estatística, Dados do Rio Grande do Sul. 2016. Disponível em http://cidades.ibge.gov.br/xtras/uf .php? lang=\&coduf=43\&search=rio-grande-do-sul, acesso em Jan. 2017.

[6] DETRAN/RS Departamento Estadual de Trânsito. Frota em Circulação no RS. Assessoria Técnica, de Gestão e Planejamento. Sistema de Consultas Integradas - SJS/RS. Disponível em http://www.detran.rs.gov.br/conteudo/ 27453/frota-do-rs, acesso em Jan. 2017

[7] Osvaldo Negrini Neto, Dinâmica dos Acidentes de Trânsito (Millennium Editora, Campinas, 2012), 4 ed.

[8] DPVAT Seguradora Líder, Boletim Estatístico. Ano 5, V. 4, Jan-Dez 2015. Disponível em https://www.seguradoralider.com.br/ Documents/boletim-estatistico/BoletimEstatistico-Ano-05-Volume-04.pdf, acesso em Jan. 2017.

[9] H.G.S. Urruth, Física e Segurança no Trânsito: Um Curso de Física e Educação para o Trânsito para Jovens e Adultos. Dissertação de Mestrado em Ensino de Física, Universidade Federal do Rio Grande do Sul, Porto Alegre, 2014.

[10] F.A. Toti e A.H. Pierson, Investigações em Ensino de Ciências 15, 527 (2010).

[11] C. Chagas, A Física no Ensino Médio Através do Estudo de Fenômenos Físicos em um Automóvel. Dissertação de Mestrado em Ensino de Ciências e Matemática, Universidade Federal do Ceará, Fortaleza, 2014.

[12] A. Brust, Física Aplicada Nas Situações Do Trânsito. Dissertação de Mestrado em Ensino de Física e Matemática, Centro Universitário Franciscano, Santa Maria, 2013.

[13] B.P. Joca, Educação para o Trânsito e a Física Aplicada no Ensino Médio. Trabalho de Conclusão de Curso de Graduação em Física - Licenciatura, Instituto Federal do Ceará, Fortaleza, 2012.

[14] W.P. Gurgel, L.M. Gomes, F.C. Ferreira e R.M. Gester, Caderno Brasileiro de Ensino de Física 37, 4305 (2015).

[15] A.R. Lucena, A Física Forense em Sala de Aula: Investigação de Acidentes de Trânsito. Trabalho de Conclusão de Curso de Graduação em Ciências 
Exatas, Universidade Estadual da Paraíba, Patos, 2014.

[16] R.M. Viana, Perícia Física de Acidente de Trânsito. Trabalho de Conclusão de Curso de Graduação em Física - Licenciatura, Universidade Federal de Rondônia, Ji-Paraná, 2009.

[17] A.L. Gomes, Física dos Acidentes de Trânsito. Trabalho de Conclusão de Curso de Graduação em Física - Licenciatura, Universidade Federal de Rondônia, Ji-Paraná, 2008.

[18] A.A. Kleer, Marcelo Resende Thielo e Arion. Kurtz dos Santos, Caderno Catarinense de Ensino de Física 14, 160 (1997).

[19] L. Abeid, As Forças de Atrito e os Freios ABS Numa Perspectiva de Ensino Médio. Dissertação de Mestrado em Ensino de Física, Universidade Federal do Rio de Janeiro, Rio de Janeiro, 2010.

[20] L. Abeid e A. Tort, Revista Brasileira de Ensino de Física 36, 2306 (2014).

[21] L. Abeid e A. Tort, Revista Física na Escola 12(1), 8 (2011).

[22] F.L. Silveira, Caderno Brasileiro de Ensino de Física 28, 468 (2011).

[23] H.O. Di Rocco, Caderno Brasileiro de Ensino de Física 26, 342 (2009).

[24] L.L. Silva, Revista Brasileira de Pesquisa em Educação em Ciências 9, 20 (2009).

[25] S. Back, Fúsica e Segurança no Trânsito: Uma Proposta Didática por uma Professora Iniciante. Dissertação de Mestrado em Educação em Ciências, Universidade Federal de Santa Maria, Santa Maria, 2013.

[26] J.F. Hair, W.C. Black, B.J. Babin, R.E. Anderson e R.L. Tatham, Análise Multivariada de Dados (Bookman, Porto Alegre, 2005), 600 p.

[27] J.T. Kirsten e W.A. Rabahy, Estatística Aplicada às Ciências Humanas e ao Turismo (Saraiva, São Paulo, 2006).

[28] S.F. Costa, Estatística Aplicada à Pesquisa em Educação (Plano Editora, Brasília, 2010).

[29] S. Samá, Estatística (A autora, Porto Alegre, 2013), v. 1,195 p.

[30] M. Olma, Consciência Sobre Rodas: Habilitação do condutor (Águia, Porto Alegre, 2016), 20 ed.

[31] BRASIL, PCN+ Ensino Médio: Orientações Educacionais Complementares aos Parâmetros Curriculares Nacionais (Mec/Semtec, Brasília, 2002).

[32] M.M. Hill e A. Hill, Investigação por Questionário (Sílabo, Lisboa, 2005). 